\title{
An Experimental Investigation of Karanja Biodiesel Production in Sarawak, Malaysia
}

\author{
Dewi Harreh (D, A. A. Saleh, A. N. R. Reddy ${ }^{D}$, and S. Hamdan \\ Faculty of Mechanical Engineering, Universiti Malaysia Sarawak, 94300 Kota Samarahan, Sarawak, Malaysia \\ Correspondence should be addressed to Dewi Harreh; dewiharreh@gmail.com
}

Received 17 October 2017; Accepted 27 December 2017; Published 30 January 2018

Academic Editor: Wei Du

Copyright (C) 2018 Dewi Harreh et al. This is an open access article distributed under the Creative Commons Attribution License, which permits unrestricted use, distribution, and reproduction in any medium, provided the original work is properly cited.

\begin{abstract}
The application of nonedible feedstock for the production of biodiesel has become an area of research interest among clean energy experts in the past few years. This research is aimed at the utilization of Pongamia pinnata (karanja), a nonedible feedstock from the state of Sarawak, Malaysia, to produce biodiesel to be known as crude karanja oil (CKO). A one-step transesterification process utilizing $7: 1-10: 1 \mathrm{wt} \%$ methanol $\left(\mathrm{CH}_{3} \mathrm{OH}\right)$ and $0.5-1.2 \mathrm{wt} \%$ sodium hydroxide $(\mathrm{NaOH})$ at $65^{\circ} \mathrm{C}$ for $1.5 \mathrm{hrs}$ has been used for the biodiesel production yielding $84 \%$ conversion. The physiochemical properties of the CKO produced revealed that it conforms with EN14214 standards for brake power (BP), brake specific fuel consumption (BSFC), and brake thermal efficiency (BTE) as they are all noted be optimal at B40.
\end{abstract}

\section{Introduction}

The diesel engine vehicles are well known as one of the largest contributors to air pollution that produce routine hazardous emissions within cities and along urban traffic routes caused by exhaust emissions [1,2]. With rapid industrialization and exponential growth of the transport sector, environmental pollution along with global warming that arise in the developing countries faces major challenges of the energy demand as well as increased environmental concerns. Impact of health problems caused by emitted of toxic air and how it is distributed within a city is crucial for sustainable development. Therefore, it has become very essential to explore a renewable energy source that will serve as an alternative fuel that will replace the consumption of petroleum fuels and reduce toxic emissions. Due to the increase in human population and awareness about climate change, attempts have been made to utilize crude karanja oil (CKO) as a feedstock for biodiesel production so as to replace costly and scarce petroleum fuels [3].

Biodiesel has been identified as a cost-effective energy source with less harmful emission and readily availability to be use as substitute fuel in the internal combustion (CI) engines. The chemical name for biodiesel is fatty acid methyl ester (FAME). It has been recognized globally around the world and is continuously been identified for its environmental friendliness and an alternative renewable energy source $[4,5]$. Recently, serious efforts are in progress by several researchers to operate $\mathrm{CI}$ engines using oil that is made from plant oil and its esters (biodiesel).

The theory of using vegetable oils as substitute for diesel engine is over a past decade. In 1910, Dr. Rudolf Diesel was the first researcher to invent a compression ignition (CI) engine using peanut oil [5]. He observed that vegetable oils are not suitable for use directly as diesel engine oil due to their high viscosity and incomplete combustion that triggers higher smoke density when compared to fossil fuel which leads to poor fuel atomization [6]. This phenomenon has been identified as potential cause of engine failure such as sticking in ring piston, choking of injectors, and formation of carbon deposits [7]. In order to minimize these problems, techniques such as oxidation process, pyrolysis, dilution, microemulsion, and transesterification have been used for production of biodiesel $[5,8]$. Among all these techniques, transesterification is the most viable and effective [9]. Biodiesel production from vegetable oils has given rise to debate of "food" versus "fuel" demand. Consequently, the demand for vegetable oil for biodiesel production has led to increase in price of the 
commodity due to its high consumption as food. Hence, the quest for alternative to edible oil for biodiesel production has given rise to use nonedible oils such as CKO. It has been identified as more sustainable and promising biodiesel feedstock when compared to edible oils [10].

Karanja tree also known as Pongamia pinnata, belongs to the family of Leguminosae. It is an evergreen tree in mediumsize, with an average height of between 12-15 $\mathrm{m}$ [11, 12]. It is normally planted along the highways for landscaping purpose because of its large canopy and showy fragrant flowers. Its roots and canals are equally useful for prevention of soil erosion. Similarly, karanja tree is highly tolerant to high salinity conditions and can be grown on most soil textures ranging from stony to sandy to clayey $[9,10]$. Malaysia, Indonesia, Thailand, East Indies, Philippines, and India are tropical and temperate Asia which offers ideal climate condition for karanja growth. In recent times, this tree has been introduced in United States and Egypt $[13,14]$. Karanja is a fast-growing tree in which its fruits get mature within 4-7 years after planting. Karanja seeds are elliptical in shape and flat pods with size $3-6 \mathrm{~cm}$ long and $2-3 \mathrm{~cm}$ wide [15]. The reddish brown of karanja fruit contains 1-2 kernels that exactly look like of the human kidney shape. The karanja seed kernel is claimed to have $30 \%-40 \%$ of oil content. The main constraints of this oil are its dark brown colour, bitter test, and disagreeable odour [11]. Karanja oil can yield 900 to $9000 \mathrm{~kg}$ per hectare. It is one of potential oils with production of 13500 million tonnes per annum but only 6\% is being utilized [16]. According to Karmee et al., karanja oil emits less amount of harmful substances and inexpensive as compared to jatropha oil [14].

The main objective of this current research is to study the production of Karanja methyl ester (KME) using locally available karanja seed feedstock as a renewable fuel. A laboratory scale experimental set-up has been established to produce the crude karanja seed oil. Base catalyzed transesterification protocol has been followed for production of KME. The biofuel properties are characterized according to EN 14214 biodiesel standards. Besides, the efficiency of a diesel engine fueled KME blends has been performed to ascertain its suitability as an alternative fuel source.

\section{Material and Method}

2.1. Material. Karanja (Pongamia pinnata) seeds have been collected from karanja tree within Universiti Malaysia Sarawak campus (UNIMAS), Kota Samarahan, Sarawak, Malaysia. Healthy karanja seeds have been identified after thorough inspection and separated from damaged seeds. The healthy seeds are deshelled, cleaned from dust, and dried in convection oven for moisture removal whereas damage seeds were discarded. Oil is extracted from the seeds using laboratory scaled chemicals such as methanol $\mathrm{CH}_{3} \mathrm{OH}$, (>99\% pure), $\mathrm{H}_{2} \mathrm{SO}_{4}$ (95-97\% pure), distilled water, and sodium hydroxide, $\mathrm{NaOH}$.

2.2. Extraction of Crude Karanja Oil. CKO was extracted using Soxhlet apparatus and mechanical expeller. Soxhlet extraction method has been selected so as to achieve the best result during extraction while hexane has been used as solvent. Hexane has been continuously refluxed until the colour of the hexane in the thimble is very clear. This process requires a longer period of time and only few amounts of oil recovered as compared to other technique $[17,18]$. The extracted CKO has been filtered and heated to eliminate solid impurities. After filtration process, the CKO then heated up to $120^{\circ} \mathrm{C}$ to remove any water content in the oil. Finally, the pretreated $\mathrm{CKO}$ has been stored in the $500 \mathrm{~mL}$ beaker sealed with aluminium foil. The stepwise extraction of CKO is shown in Figure 1.

2.3. Measurement of Free Fatty Acid. Free Fatty Acid (FFAs) content in the CKO has been determined using standard titrimetric methods. It has been reported that the amount of potassium hydroxide, $\mathrm{KOH}$, that requires neutralizing the fatty acid contained in CKO is $1 \mathrm{mg}$ of FAME [17-19]. According to Azhari et al. [19], high amount of soap would be produced simultaneously when transesterification reaction of the feedstock contains a high amount of FFA than the required maximum amount of basic homogenous catalyst. Thus, to overcome this reaction, an alternative mechanism can be applied. For example, enzymes, solid resins, homogenous acid catalyst, or supercritical process has been used [20, 21]. Initially, $200 \mathrm{ml}$ beaker has been filled with $15 \mathrm{ml}$ of $95 \%$ ethanol and $15 \mathrm{ml}$ of diethyl ether along with 5 drops of phenolphthalein indicator. Afterwards, $40 \mathrm{~g}$ of $\mathrm{CKO}$ was poured into a conical flask and titrated with $\mathrm{KOH}$ solution with continuous stirring until pink colour appear.

2.4. Karanja Biodiesel Production. For the second step, base catalyzed transesterification process has been conducted to produce KME. Sodium hydroxide $(\mathrm{NaOH})$ has been utilized as a base catalyst. The sodium methoxide solution has been prepared by mixing the different methanol to oil ratio by volume $(7: 1,8: 1,9: 1$, and $10: 1)$ with $\mathrm{NaOH}$ and stirred at $250 \mathrm{rpm}$ using a magnetic stirrer and heated the contents continuously for $90 \mathrm{~min}$ [22]. Afterwards, the reaction mixture has been left to settle overnight so as to separate the mixture into 2 different layers: the upper layer being the methanolwater fraction and the bottom layer being the methyl ester. The mixture has been allowed to settle completely, and the bottom layer containing glycerol is removed. The KME is washed with distilled water to remove impurities such as catalyst and excess methanol [23]. The biodiesel obtained is again heated until $60^{\circ} \mathrm{C}-80^{\circ} \mathrm{C}$ until it turns clear. Lastly, the biodiesel is kept in a beaker and sealed with aluminium foil to prevent contamination. Sequential of karanja biodiesel production was shown in Figure 2.

2.5. Engine Performance Test. The engine performance test has been carried out using Techno-mate, TNM-TDE-700 machine as shown in Figure 3. In the study, various combination of blends has been prepared to identify the recommended biodiesel blend. B10 (10\% KB + 90\% PD), B20 (20\% $\mathrm{KB}+80 \% \mathrm{PD}), \mathrm{B} 30(30 \% \mathrm{~KB}+70 \% \mathrm{PD}), \mathrm{B} 40(40 \% \mathrm{~KB}+$ $60 \% \mathrm{PD}), \mathrm{B} 50(50 \% \mathrm{~KB}+50 \% \mathrm{PD})$, and $\mathrm{B} 100(100 \% \mathrm{~KB})$ blends have been prepared and tested using diesel engine to evaluate the engine performance [24]. The performance 


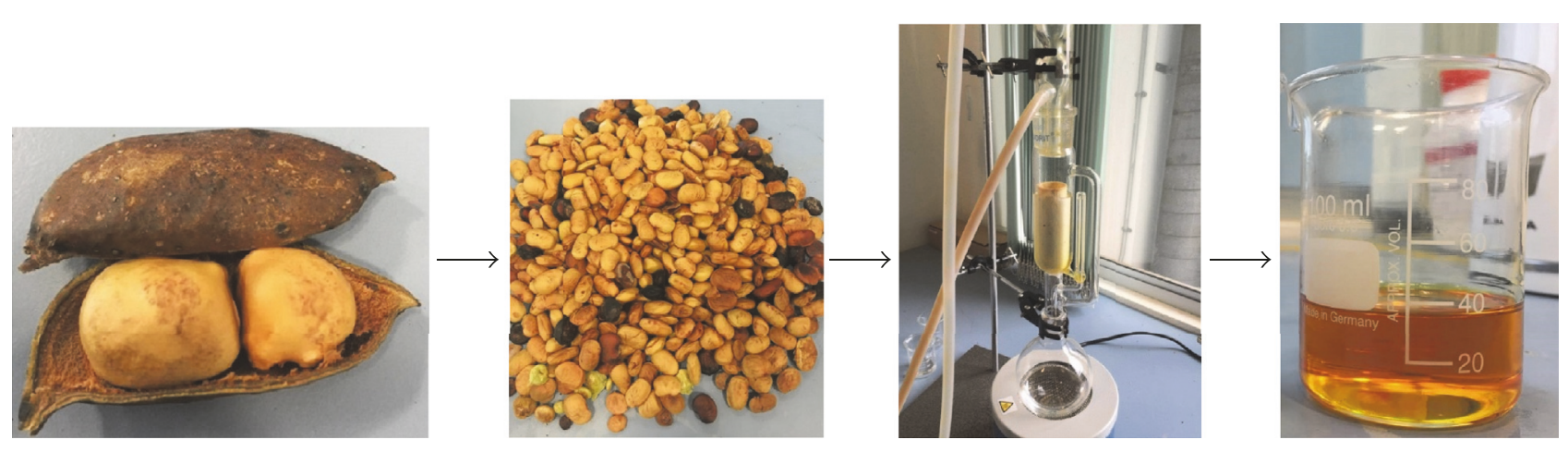

FIGURE 1: Crude karanja oil extraction process.
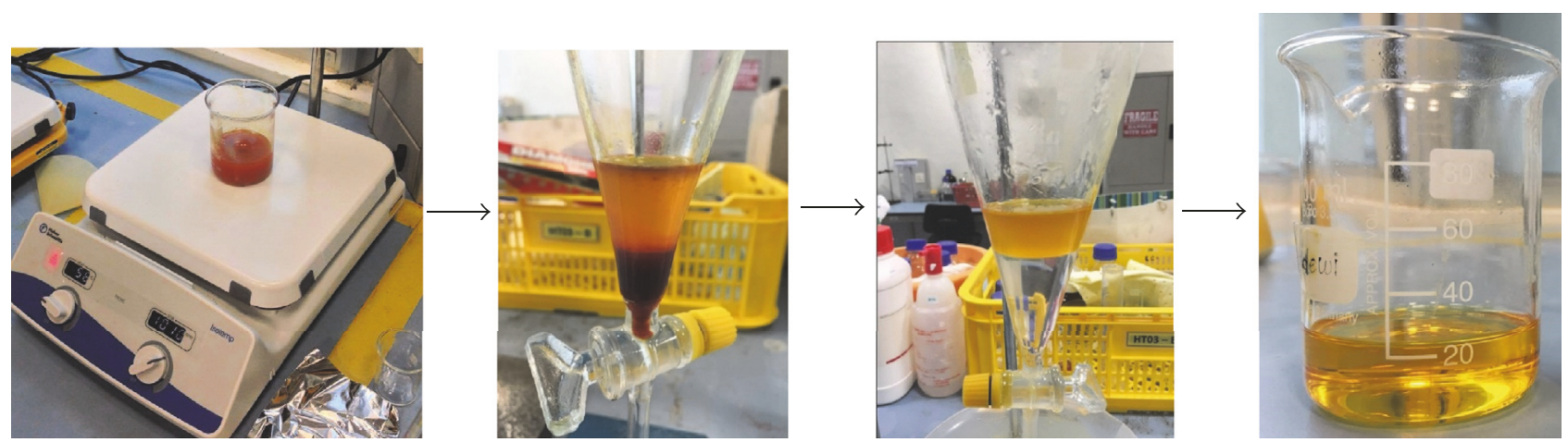

FIGURE 2: Karanja biodiesel production by transesterification.

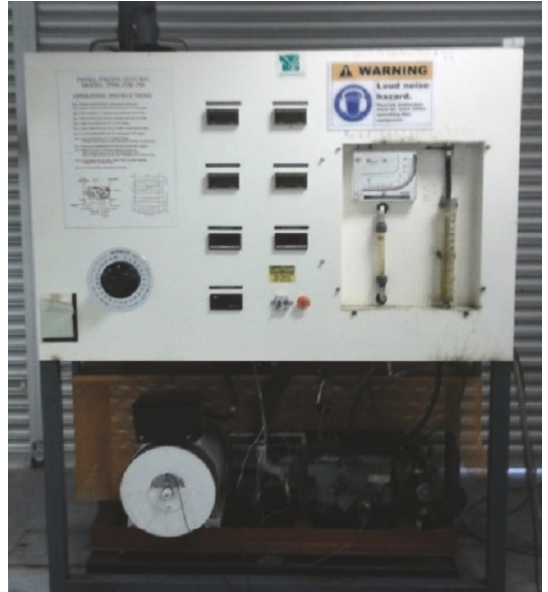

Figure 3: Diesel Engine Performance Test Bed (Techno-mate, TNM-TDE-700).

parameters such as brake power (BP), brake specific fuel consumption (BSFC), and brake thermal efficiency (BTE) have been calculated using the collected test data $[24,25]$.

\section{Results and Discussion}

3.1. Titrimetric Results on Crude Karanja Oil. Table 1 shows the measurement of FFA content in CKO is essential in
TABLE 1: Free Fatty Acid analysis results of crude karanja oil.

\begin{tabular}{lcccc}
\hline Cycle & $\mathrm{W}(\mathrm{g})$ & $\mathrm{V}(\mathrm{ml})$ & $\mathrm{M}(\mathrm{mol})$ & Acid value $(\%)$ \\
\hline First & 2.09 & 2.4 & 0.1 & 0.645 \\
Second & 2.02 & 2.39 & 0.1 & 0.666 \\
Third & 2.3 & 2.52 & 0.1 & 0.615 \\
\hline
\end{tabular}

the transesterification process for biodiesel production [26]. Titration is done using $0.1 \mathrm{~mol}$ of $\mathrm{KOH}$ solution and it has been repeated 3 times to obtain the average value in order to eliminate parallax errors. Karanja oil was found less than $1 \%$. Thus, one-step transesterification has been carried out. From the titration method, the FFA content in CKO has been found to be within the ranges of $0-1 \%$, which is lower $1 \%$. The best conversion method has been one-step transesterification.

3.2. Effect of Particle Size of the Seeds to Oil Yield Ratio. Variations of the particle size occur during size reduction in crushing or grinding seeds. Particle size is one critical parameter when using solvent extraction [27]. Small size of seed particles will facilitate solvent extraction by reducing the distances that solvent and oil must diffuse in and out of the seed particle during the extraction process. The smaller the particle size, the greater the interfacial area between the solid and the solvent, thus increasing the rate of transfer of the oil and solvent outside of the seed particles [28]. Figure 4 shows 


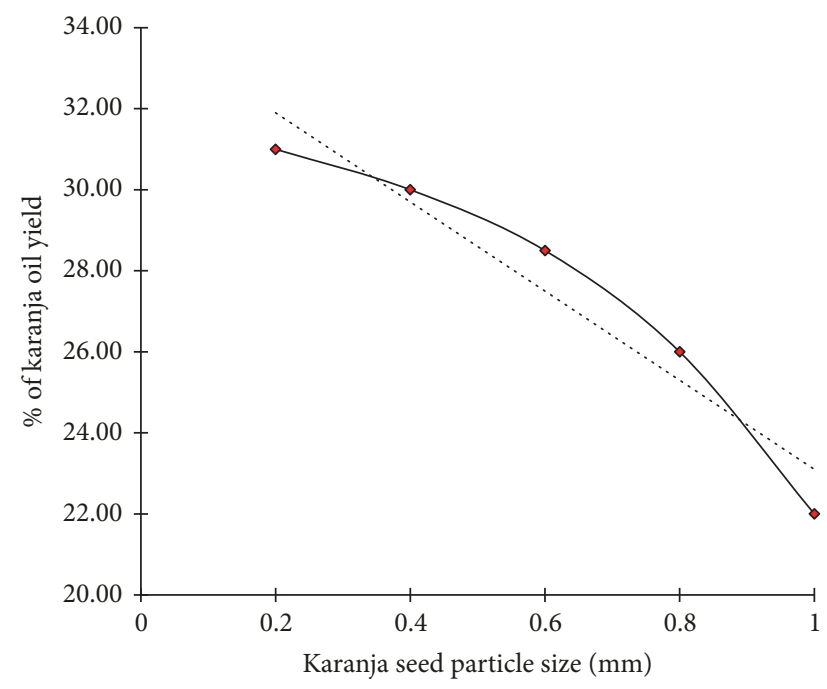

FIGURE 4: Biodiesel conversion by changing the particle size.

that the smaller size of the particle will produce high amount of oil yield.

\subsection{Karanja Biodiesel Yield Analysis}

3.3.1. The Effect of Methanol to Oil Ratio. It has been reported that alcohol to oil ratio has a significant parameter, affecting the conversion yield of triglycerides to methyl ester [29]. According to stoichiometric ratio for transesterification process, 1 mol. of triglyceride and $3 \mathrm{~mol}$. of alcohol are required to yield $1 \mathrm{~mol}$. of glycerol and $3 \mathrm{~mol}$. of fatty acid alkyl esters. Nevertheless, transesterification is an equilibrium reaction where large amount of alcohol is needed to drive the reaction to right. Relationship between molar ratio and esters yield are not affected by iodine value, peroxide, acid, and saponification. From Figure 5, the feasible proportion that will induce higher KME yield increased as the methanol to oil ratio increases. Nevertheless, with a later increase of molar ratio to $10: 1$, the lower yield obtained is $75.45 \%$. This was due to the difficulties in separation of glycerol when the molar ratio is higher, as the excess methanol delays the decantation by gravity, thus causing the yield decreases since there are still glycerol leftovers in the biodiesel phase Ac [30, 31]. Krisnangkura and Simamaharnnop [32] have stated that the leftovers glycerol in solution helps to drive the equilibrium back to the left, thus resulting in lowering the biodiesel yield.

3.3.2. The Effect of Catalyst to Oil Ratio. Figure 6 shows the influence of concentration $\mathrm{NaOH}$ varied in the range from $0.5 \%$ to $1.2 \%$ (wt/wt of oil). The best result has been achieved at $84 \%$ with a concentration of $1 \%$ of catalyst. As a consequence, the further increase in concentration of catalyst causes the formation of an emulsion which increases the viscosity, thus leading to gels development that prohibit the separation of glycerol, thus reducing the yield of methyl ester [33].

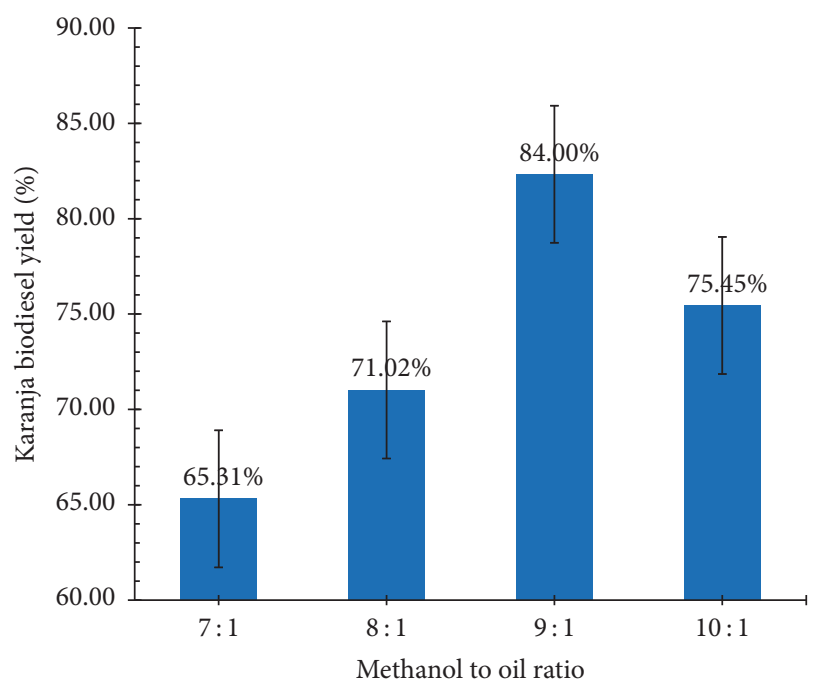

FIGURE 5: Biodiesel conversion by changing methanol to oil ratio.

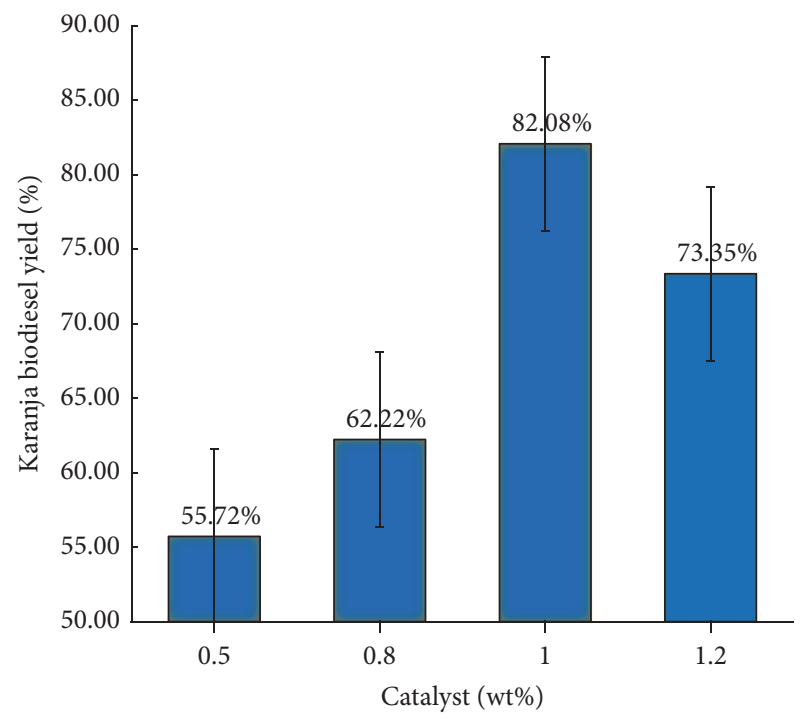

FIGURE 6: Biodiesel conversion by changing catalyst to oil ratio.

3.3.3. Effect of Equipment Used. Orbital shaker (OS) and magnetic stirrer cum heater (MS) have been used to study on how different types of equipment can affect the biodiesel yield conversion. Sodium hydroxide has been used as a catalyst with concentration of $1 \%$ when methanol to oil ratio was $6: 1$ for 90 minutes. From the results shown in Figure 7, OS had successfully converted KME by $86 \%$ when compared to MS which obtained yield is only $72 \%$. OS has shown a better and more complete of mixing process for biodiesel conversion. Also, it provides a more balance which contributes to higher conversion efficiency as compared to MS. Therefore, it can be concluded that OS is more reliable equipment to be used in production of methyl esters.

3.4. FTIR Analysis. The infrared spectrum of the each of the results is compared and analyzed to identify the functional 
TABLE 2: Properties of crude karanja oil before transesterification and test methods used.

\begin{tabular}{lcr}
\hline Properties & Karanja oil & Test method \\
\hline Density, g/mL $15^{\circ} \mathrm{C}$ & 0.924 & EN ISO 3675 \\
Kinematic viscosity $\left(40^{\circ} \mathrm{C}\right), \mathrm{mm}^{2} / \mathrm{s}$ & 27.82 & EN ISO 3104 \\
Water content, $\%$ & 10.20 & EN ISO 12937 \\
FFA, $\%$ & 15.62 & ASTM D5555 \\
Saponification number, mg/g & 186.4 & ASTM D5558 \\
Acid number, $\mathrm{mg} \mathrm{KOH} / \mathrm{g}$ oil & 31.24 & EN 14104 \\
\hline
\end{tabular}

TABLE 3: Properties of karanja methyl esters and test methods used.

\begin{tabular}{|c|c|c|c|}
\hline Property & CKO methyl ester & EN 14214/ASTM limits & Test methods \\
\hline Acid value, $\mathrm{KOH}, \mathrm{mg} \mathrm{g}^{-1}$ & 0.17 & $0.5 \max$ & EN 14104 \\
\hline Water content, $\%$ & 0.038 & $0.05 \% \max$ & EN ISO 12937 \\
\hline Kinematic viscosity $\left(40^{\circ} \mathrm{C}\right), \mathrm{mm}^{2} / \mathrm{s}$ & $4.66 \pm 0.02$ & $3.50-5.00$ & EN ISO 3104 \\
\hline Cloud point, ${ }^{\circ} \mathrm{C}$ & 6 & NS & EN14214 \\
\hline Pour point, ${ }^{\circ} \mathrm{C}$ & 3 & NS & ASTM D 97 \\
\hline Flash point, ${ }^{\circ} \mathrm{C}$ & 212 & $120 \mathrm{~min}$ & EN22719 \\
\hline Density $\left(15^{\circ} \mathrm{C}\right), \mathrm{g} \mathrm{cm}^{-3}$ & 0.883 & $0.860-0.900$ & EN ISO 3675 \\
\hline Group 1 metals $(\mathrm{Na}+\mathrm{K}), \mathrm{mg} / \mathrm{kg}$ & & 0.5 & EN14214 \\
\hline Free glycerin, wt $\%$ & 0.0064 & 0.02 & ASTM D6584 \\
\hline Total glycerin, wt $\%$ & 0.082 & 0.240 & ASTM D6584 \\
\hline Phosphorus, mg/kg & 0.04 & $<4-10$ & ASTM D4951 \\
\hline Monoglyceride content, wt $\%$ & 2.63 & $<0.8$ & EN4214 \\
\hline Diglyceride content, wt $\%$ & 0.78 & $<0.2$ & EN4214 \\
\hline Triglyceride content, wt $\%$ & 0.06 & $<0.2$ & EN4214 \\
\hline
\end{tabular}

NS: not specified.

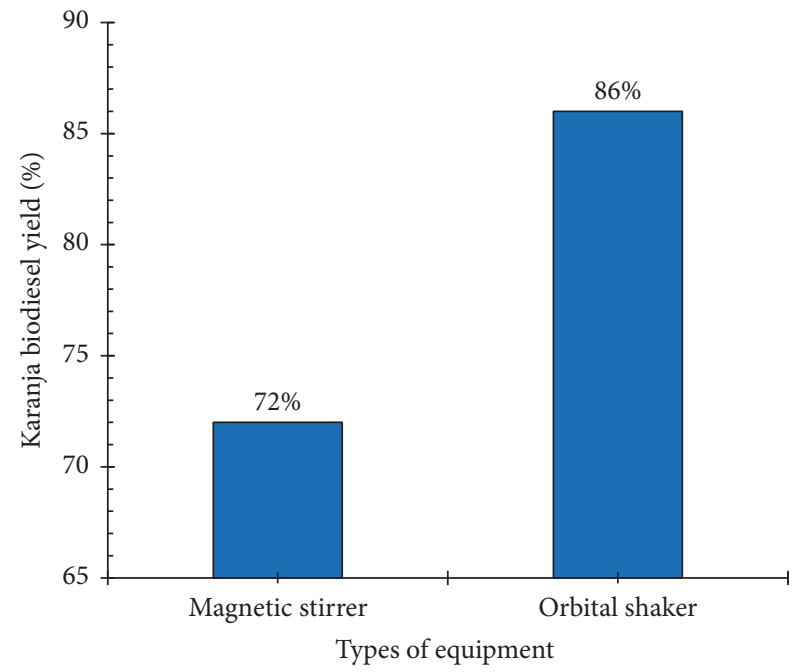

Figure 7: Biodiesel conversion by changing type of equipment.

group, respectively. In the infrared spectrum of karanja biodiesel (Figure 8(a)) and conventional diesel (Figure 8(b)), the existing functional group is alkane $\mathrm{C}-\mathrm{H}$ bond $2800 \mathrm{~cm}^{-1}$ to $3000 \mathrm{~m}^{-1}$ and $1350 \mathrm{~cm}^{-1}$ to $1480 \mathrm{~m}^{-1}$. Although it has been observed that both biodiesel and diesel have the functional group of $\mathrm{C}-\mathrm{H}$ bond, only biodiesel displays the oxygen functional group such as $\mathrm{C}=\mathrm{O}$ and $\mathrm{C}-\mathrm{O}$. This means that biodiesel, with the existence of oxygen functional group, will promote cleaner and complete combustion.

3.5. Properties of Biodiesel. Tables 2 and 3 show the analysis and the test methods adopted for the determination of CKO methyl esters properties.

3.6. Engine Performance Test. The performance of engine using diesel, KME blended with diesel, and CKO is presented and discussed below.

Figure 9 shows the influence of load on brake horse power (BHP) for different fuels. The graph indicates that BP increases up to $70 \%$ load as the load increases and then decreases for all the fuel samples. It can be observed that the BP increases up to B40 and then decreases when compared with different types of blends at different loads [34]. According to Stalin and Prabhu [24], BP for blends $\mathrm{B} 10$ to $\mathrm{B} 30$ is higher when compared with various blends different load. From the figure, it has been found that brake power for B40 is the best alternative and nearly close to the conventional diesel [20], while the BP for B50 and B100 is less than commercial diesel. Hence, it can be concluded that B40 is suitable blend to be used in diesel engine without modifications. Also, price of B 40 can be considerably reduced as compared to commercial diesel. 


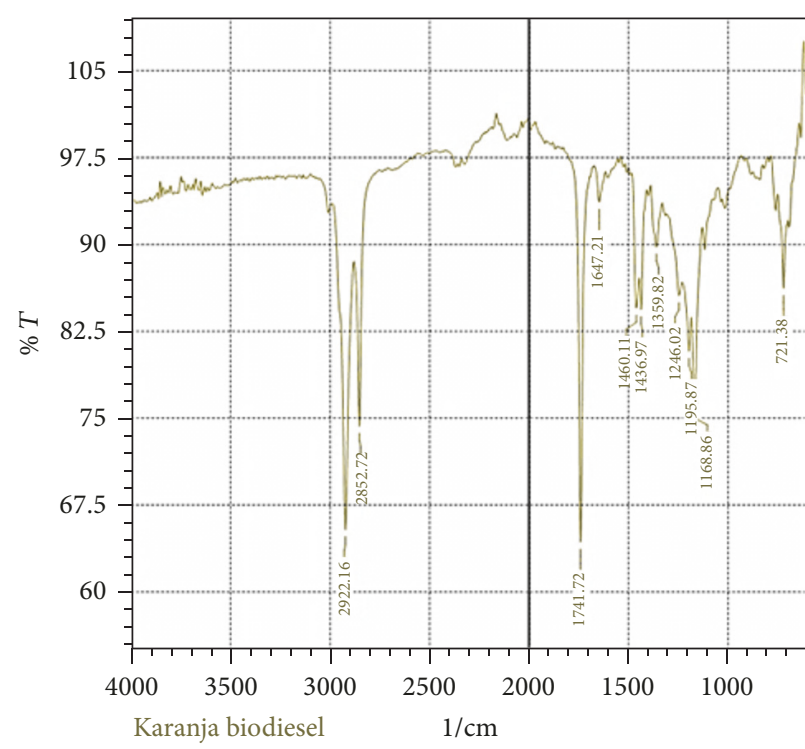

(a)

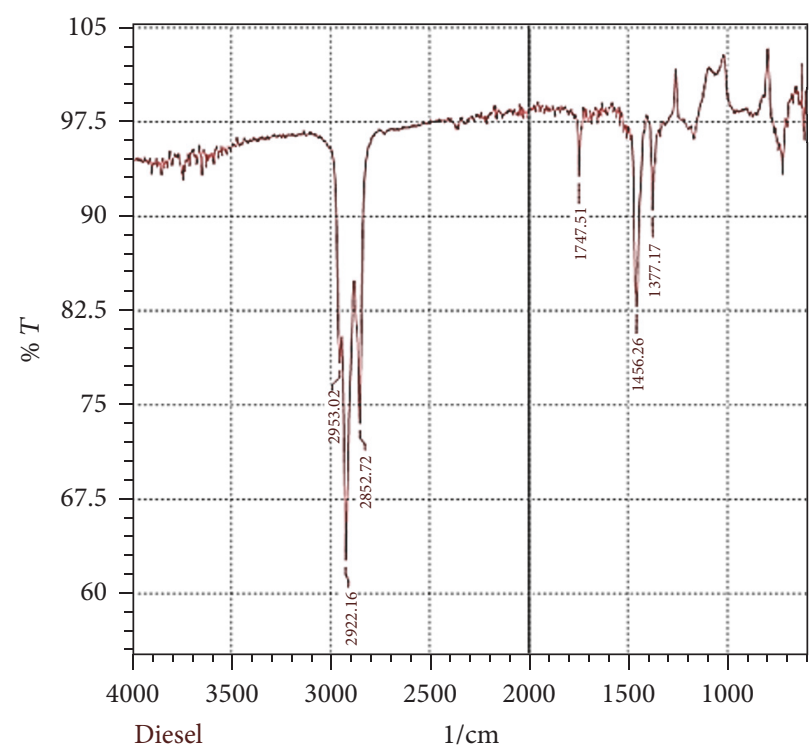

(b)

FIGURE 8: FTIR spectrum of (a) karanja biodiesel and (b) conventional diesel.

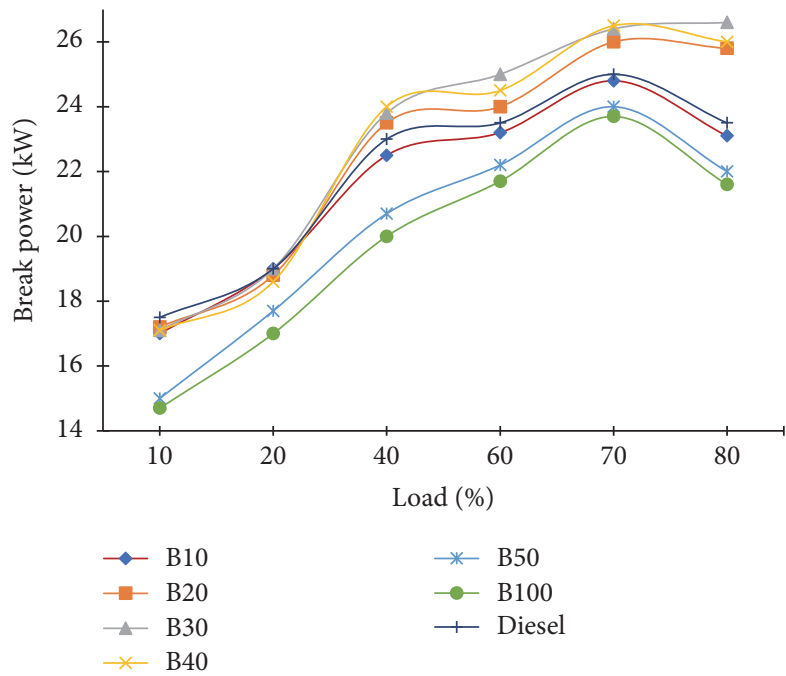

FIGURE 9: Break power for different loads.

Figure 10 shows the variation of brake thermal efficiency (BTE). The BTE of KME blends have been found to be on increasing trend up to $70 \%$ as the load increases and started to decrease for all blends tested. B50 and B100 show a low brake thermal efficiency. According to Raheman and Phadatare [35], this lower brake thermal efficiency obtained for B60 and B100 could be due to reduction in calorific value and increase in fuel consumption. Besides, it has been observed that the BTE for B40 is nearly the same as the commercial diesel. According to Nagarhalli and Nandedkar [36] no significant change in efficiency is shown in the $40 \%$ and $60 \%$ blends, thus making them highly recommended.

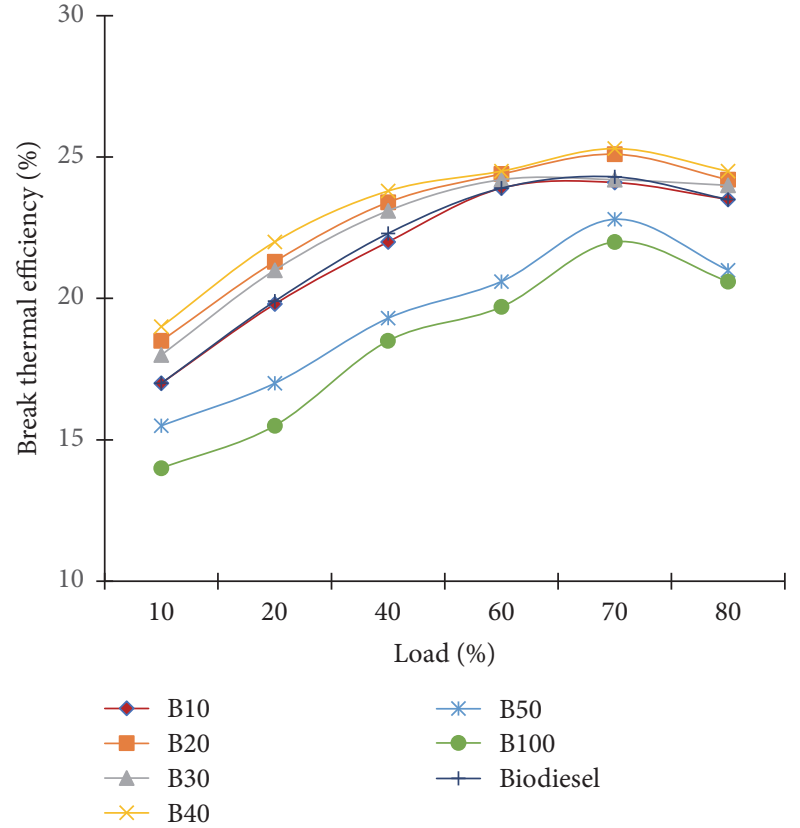

FIGURE 10: Brake thermal efficiency for different loads.

The variation of brake specific fuel consumption (BSFC) at different loads is shown in Figure 11. Results show that BSFC decreased as the load increases and then BSFC increases for all the fuel samples tested. Similar results have been reported by Stalin and Prabhu [24]. This can be linked with the test results of the BHP. The SFC for B10, B15, and B20 is nearly the same as that of commercial diesel. The results obtained for B40, B50, and B100 are found to be increasing 


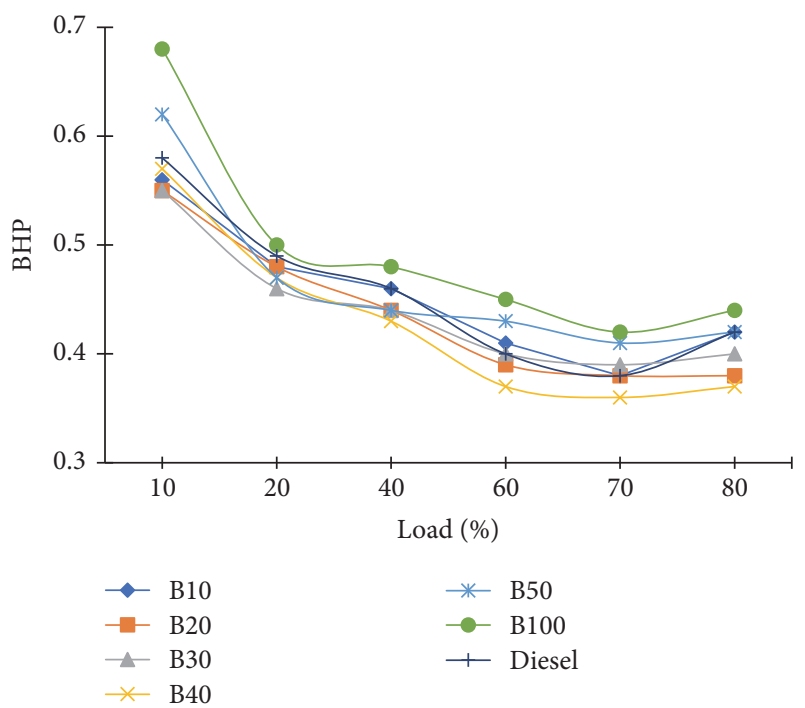

FIGURE 11: Beak horsepower for different loads.

in specific fuel consumption (SFC) but still less than SFC for commercial diesel.

\section{Conclusions}

This research has successfully investigated the potential of crude karanja oil (CKO) as a sustainable feedstock from Sarawak, Malaysia, for biodiesel production. Soxhlet extraction has been used to produce $\mathrm{CKO}$, while biodiesel has been produced by transesterification of CKO using $\mathrm{NaOH}$ and $\mathrm{MeOH}$. Physiochemical properties of CKO and karanja biodiesel were investigated according to EN 14214 biodiesel standards. Besides, the biodiesel blends fueled engine test results such as BHP, BTE, and BSFC have been used to describe the suitability of KME as substitute fuel for diesel engines and the performance this engine has been found to be optimum.

\section{Conflicts of Interest}

The authors declare that they have no conflicts of interest.

\section{Acknowledgments}

This research was supported by the Department of Mechanical and Manufacturing Engineering, Faculty of Engineering, University Malaysia Sarawak, Malaysia.

\section{References}

[1] Diesel Engines and Public Health - Union of Concerned Scientists.

[2] I. A. Reşitoğlu, K. Altinişik, and A. Keskin, "The pollutant emissions from diesel-engine vehicles and exhaust aftertreatment systems," Clean Technologies and Environmental Policy, vol. 17, no. 1, pp. 15-27, 2015.
[3] G. Joshi, D. S. Rawat, B. Y. Lamba et al., "Transesterification of Jatropha and Karanja oils by using waste egg shell derived calcium based mixed metal oxides," Energy Conversion and Management, vol. 96, pp. 258-267, 2015.

[4] D. R. Tobergte and S. Curtis, "High temperature solid-catalized transesterification for biodiesel production," Journal of Chemical Information and Modeling, vol. 53, no. 9, pp. 1689-1699, 2013.

[5] R. Alam, "Studies on the properties of karanja oil for probable industrial application master of science in chemistry," Technology, pp. 1-29, 2002.

[6] M. N. Nabi, S. M. N. Hoque, and M. S. Akhter, "Karanja (Pongamia Pinnata) biodiesel production in Bangladesh, characterization of karanja biodiesel and its effect on diesel emissions," Fuel Processing Technology, vol. 90, no. 9, pp. 1080-1086, 2009.

[7] P. K. Srivastava and M. Verma, "Methyl ester of karanja oil as an alternative renewable source energy," Fuel, vol. 87, no. 8-9, pp. 1673-1677, 2008.

[8] P. V Rao, "Effect of properties of Karanja methyl ester on combustion and NOx emissions of a diesel engine," Journal of Petroleum Technology and Alternative Fuels, vol. 2, pp. 63-75, 2011.

[9] S. Ismail, S. A. Abu, R. Rezaur, and H. Sinin, "Biodiesel Production from Castor Oil and Its Application in Diesel Engine Biodiesel Production from Castor Oil and Its Application in Diesel Engine," Renewable Energy, vol. 31, no. 2, p. 90, 2016.

[10] D. Vashist and M. Ahmad, "Comparative Study of Performance and Emission Characteristics of a Diesel Engine Fueled by Castor and Jatropha Methyl Ester with the Help of $t$ Test," vol. 2, no. 2, pp. 61-67, 2012.

[11] S. N. Bobade and V. B. Khyade, "Detail study on the Properties of Pongamia Pinnata ( Karanja ) for the Production of Biofuel," Research Journal of Chemical Sciences, vol. 2, no. 7, pp. 16-20, 2012.

[12] A. E. Atabani, A. S. Silitonga, H. C. Ong et al., "Non-edible vegetable oils: a critical evaluation of oil extraction, fatty acid compositions, biodiesel production, characteristics, engine performance and emissions production," Renewable \& Sustainable Energy Reviews, vol. 18, pp. 211-245, 2013.

[13] L. C. Meher, S. N. Naik, and L. M. Das, "Methanolysis of Pongamia pinnata (karanja) oil for production of biodiesel," Journal of Scientific \& Industrial Research, vol. 63, no. 11, pp. 913918, 2004.

[14] S. K. Karmee, P. Mahesh, R. Ravi, and A. Chadha, "Kinetic study of the base-catalyzed transesterification of monoglycerides from Pongamia oil," Journal of the American Oil Chemists' Society, vol. 81, no. 5, pp. 425-430, 2004.

[15] E. S. Ahmed, N. H. Twaty, K. G. Fakiha, and M. A. Bibars, "Mutageneic and antimutagenic effects of some plant extracts in Drosophilla melanogaster," Nature and Science, vol. 8, no. 4, pp. 77-82, 2010.

[16] M. S. Khayoon, M. A. Olutoye, and B. H. Hameed, "Utilization of crude karanj (Pongamia pinnata) oil as a potential feedstock for the synthesis of fatty acid methyl esters," Bioresource Technology, vol. 111, pp. 175-179, 2012.

[17] C. N. Ibeto, C. O. Okoye, and A. U. Ofoefule, "Comparative study of the physicochemical characterization of some oils as potential feedstock for biodiesel production," ISRN Renewable Energy, vol. 2012, pp. 1-5, 2012.

[18] P. K. Sahoo and L. M. Das, "Process optimization for biodiesel production from Jatropha, Karanja and Polanga oils," Fuel, vol. 88, no. 9, pp. 1588-1594, 2009. 
[19] Azhari, M. Faiz, R. Yunus, T. I. Ghazi, and C. T. Yaw, "Reduction of free fatty acids in crude jatropha curcas oil via an esterification process," International Journal of Engineering and Technology, vol. 5, no. 2, pp. 92-98, 2008.

[20] M. A. Kelkar, P. R. Gogate, and A. B. Pandit, "Intensification of esterification of acids for synthesis of biodiesel using acoustic and hydrodynamic cavitation," Ultrasonics Sonochemistry, vol. 15, no. 3, pp. 188-194, 2008.

[21] J. M. Marchetti and A. F. Errazu, "Esterification of free fatty acids using sulfuric acid as catalyst in the presence of triglycerides," Biomass \& Bioenergy, vol. 32, no. 9, pp. 892-895, 2008.

[22] H. M. Imran, A. H. Khan, M. S. Islam, R. Niher, A. Sujan, and A. S. Chowdhury, "Utilization of Karanja (Pongamia pinnata) as a Major Raw Material for the Production of Biodiesel," Dhaka University Journal of Science, vol. 60, no. 2, 2012.

[23] K. S. Suresh, J. J. Allen, A. Prabhu, and N. Vijaya, Preparation and Performance Analysis of Nerium Oil Blended, vol. 2, 1 edition, 2014, 51-57.

[24] R. Stalin and H. J. Prabhu, "Performance test of IC engine using karanja biodiesel blending with diesel," Journal of Engineering and Applied Sciences, vol. 2, no. 5, pp. 32-34, 2007.

[25] S. Gangil, R. Singh, P. Bhavate, D. Bhagat, and B. Modhera, "Evaluation of engine performance and emission with methyl ester of Karanja oil," Perspectives in Science, vol. 8, pp. 241-243, 2016.

[26] A. Bulletin and T. Page, Determination of free fatty acids (FFA) in edible oils with 859 Titrotherm, 3-6.

[27] P. Mahanta and A. Shrivastava, "Technology development of bio-diesel as an energy alternative," 1-19.

[28] T. Chidzanira, nvestigation of the Effect of Particle Size on Froth Stability, 2016.

[29] A. Demirbas, "Progress and recent trends in biodiesel fuels," Energy Conversion and Management, vol. 50, no. 1, pp. 14-34, 2009.

[30] V. S. N. Ijayan and S. R. Ubha, "Effect of Process Parameters in the Production of Biodiesel through Transesterification - A Review," Canadian Chemical Transactions, vol. 3, no. 3, 2015.

[31] A. K. Vuppaladadiyam and S. Sowmya, "Transesterification of Pongamia pinnata Oil Using Base Catalysts: A Laboratory Scale Study Abstract: 2," Materials and Methods, vol. 3, no. 1, pp. 113118, 2013.

[32] K. Krisnangkura and R. Simamaharnnop, "Continuous transmethylation of palm oil in an organic solvent," Journal of the American Oil Chemists' Society, vol. 69, no. 2, pp. 166-169, 1992.

[33] G. Anastopoulos, Y. Zannikou, S. Stournas, and S. Kalligeros, "Transesterification of vegetable oils with ethanol and characterization of the key fuel properties of ethyl esters," Energies, vol. 2, no. 2, pp. 362-376, 2009.

[34] M. Subbiah, "Experimental analysis of combustion ignition engine using bio-diesel," International Journal of Innovative Science, Engineering and Technology, vol. 2, no. 6, pp. 527-532, 2015.

[35] H. Raheman and A. G. Phadatare, "Emissions and Performance of Diesel Engine from Blends of Karanja Methyl Ester (Biodiesel) and Diesel," Biomass \& Bioenergy, vol. 27, no. 4, pp. 393-397, 2004.

[36] M. V. Nagarhalli and V. M. Nandedkar, "Effect of injection pressure on emission and performance characteristics of Karanja biodiesel and its blends in C . I . Engine," International Journal of Applied Engineering Research, vol. 1, no. 2, pp. 786-792, 2011. 


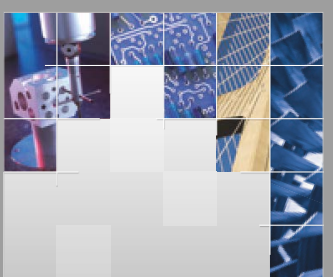

\section{Enfincering}
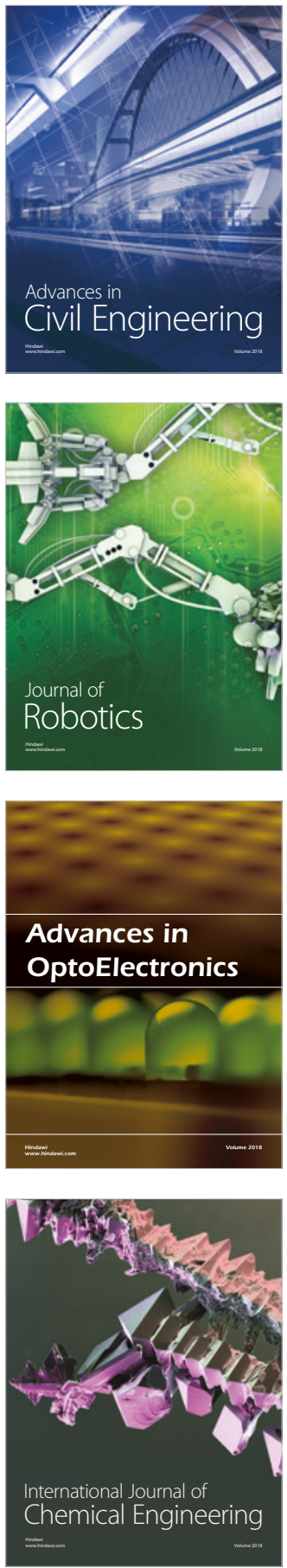

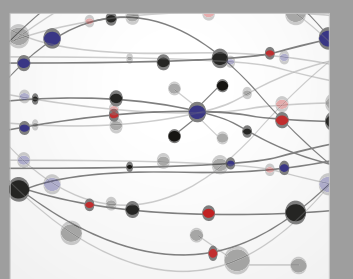

\section{Rotating \\ Machinery}

The Scientific World Journal

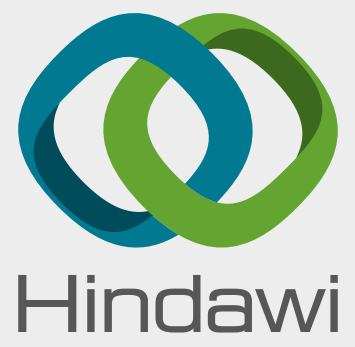

Submit your manuscripts at

www.hindawi.com
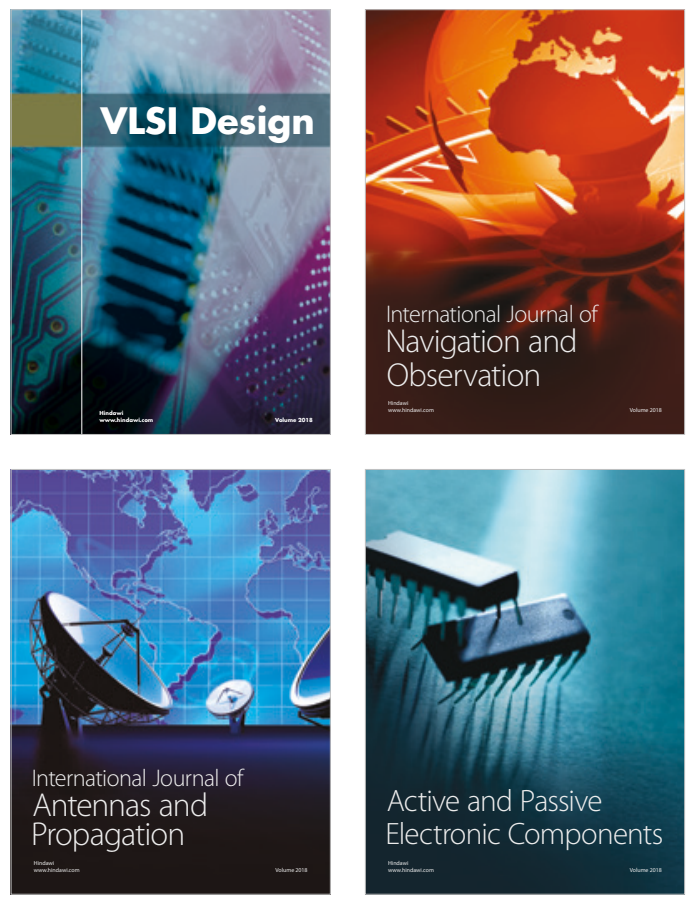
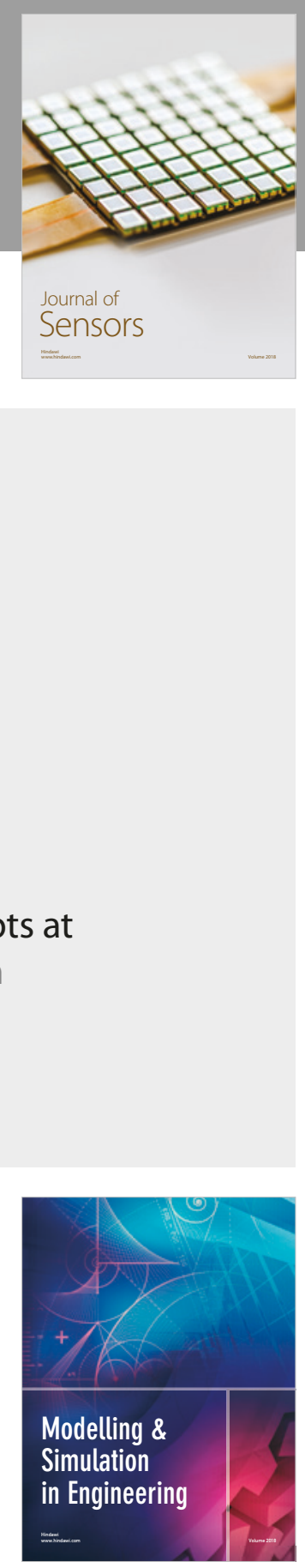

\section{Advances \\ Multimedia}
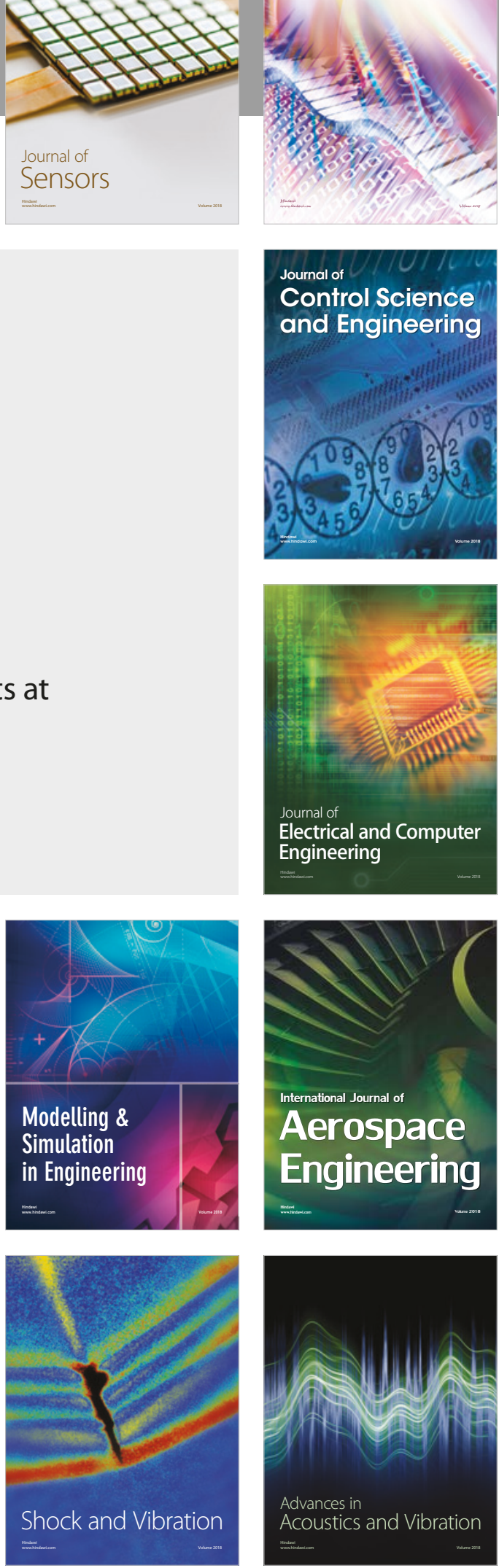